\title{
Localization of the Nerve Entry Points of Thigh Adductor Muscles by Spiral Computed Tomography: A Novel Anatomical Guide for Chemical Neurolysis in Treating Muscle Spasticity
}

\author{
Localización de los Puntos de Entrada del Nervio de los Músculos Aductores del Muslo \\ Mediante Tomografía Computarizada Espiral: Una Nueva Guía Anatómica para la \\ Neurolosis Química en el Tratamiento de la Espasticidad Muscular
}

Yimei Chen'; Meng Wang'; Xiaoming Zhang'; Tijiang Zhang ${ }^{3}$ \& Shengbo Yang $^{1 *}$

CHEN, Y.; WANG, M.; ZHANG, X.; ZHANG, T. \& YANG, S. Localization of the nerve entry points of thigh adductor muscles by spiral computed tomography: A novel anatomical guide for chemical neurolysis in treating muscle spasticity. Int. J. Morphol., 36(3):871$876,2018$.

SUMMARY: The nerve entry points (NEPs) cannot yet be accurately localized for the treatment of thigh adductor muscles spasticity in chemical neurolysis. The aim of this study was to identify the location and depth of the NEPs of thigh adductor muscles by spiral computed tomography (CT) and bony landmarks. Forty lower limbs of twenty adult cadavers were dissected in supine position. A curved line on skin surface from the tip of greater trochanter of femur to the center of pubic tubercle was designated as the horizontal reference line $(\mathrm{H})$. Another curved line from the tip of great trochanter to the lateral epicondyle of femur was designated as the longitudinal reference line (L). Following dissection, the NEPs were labeled with barium sulfate, and their body surface projection points (P) were determined by spiral CT. Projection of NEP in the opposite direction was designated as $\mathrm{P}^{\prime}$. The percentage location of the intersections (PH and PL) of P with the $\mathrm{H}$ and L and the percentage depth of NEPs were determined with the Syngo system. The PH for the NEP of pectineus, gracilis, adductor longus, adductor brevis and adductor magnus muscles branch were located at 76.41 $\pm 0.71 \%, 93.85 \pm 2.07$ $\%, 92.05 \pm 2.15 \%, 80.75 \pm 1.20 \%$ and $88.08 \pm 1.09 \%$ of the $\mathrm{H}$, respectively. The PLwere at $1.64 \pm 0.04 \%, 29.89 \pm 1.90 \%, 16.06 \pm 1.32 \%$, $11.66 \pm 0.11 \%$ and $22.94 \pm 0.90 \%$ of the L, respectively. The depth of NEP from P points were at $17.52 \pm 0.52 \%, 38.38 \pm 2.75 \%, 20.88 \pm 0.79$ $\%, 20.35 \pm 0.82 \%$ and $39.52 \pm 0.67 \%$ of PP', respectively. These results help to carry out more precise localization of the NEPs. It should provide a novel anatomical guide for improving the efficacy and efficiency of chemical neurolysis in treating thigh adductor muscle spasticity.

KEY WORDS: Nerve entry points; Localization; Thigh adductor muscles; Spasticity; Spiral computed tomography.

\section{INTRODUCTION}

Muscle spasticity is a life threatening and high cost pathophysiological event, which may result from central nervous system damages such as stroke, brain trauma, spinal cord injury, or multiple sclerosis (Ward, 2008; Yang et al., $2017 \mathrm{a}, \mathrm{b})$. The thigh adductor muscles include gracilis, adductor longus, adductor brevis, adductor magnus and pectineus muscle. The first four muscles are innervated by obturator nerve, while pectineus muscleis innervated by femoral nerve in $90 \%$ cases (Woodburne, 1960; Yoshida $e t$ al., 2017). These muscles control the adduction and lateral rotation of the thigh. Individuals suffering from thigh adductor muscle spasticity usually present scissors-crossed steps, wide-spread gait, and/or balance deficits (Alabdulwahab et al., 2010). Apart from drug treatment (Murphy et al., 2008), current commonly used treatment methods on thigh adductor muscles spasticity include adductor lengthening and obturator neurotomy (Khot et al., 2008; Qureshi et al., 2013), chemodenervation through intramuscular injection of botulinum toxin $\mathrm{A}$, and phenol or ethanol injection to nerve trunk or its muscular branches,

\footnotetext{
${ }^{1}$ Department of Anatomy, Zunyi Medical College, Zunyi, Guizhou, People's Republic of China.

${ }^{2}$ Department of Molecular and Cellular Biology, Baylor College of Medicine, Houston, Texas, USA.

${ }^{3}$ Department of Radiology, The First Affiliated Hospital of Zunyi Medical College, Zunyi, Guizhou, People's Republic of China.
} 
i.e., chemical neurolysis (Cioncoloni et al., 2014; Lam et al., 2015). However, the key for a successful chemical neurolysis is to precisely locate the blocking targets, i.e., nerve entry points (NEPs) to the muscles (Hu et al., 2017).

One study, by using body surface bony landmarks and a longitudinal reference line, has described the superior-inferior relationship between the "Extramuscular Motor Points" (equavelant to "Nerve Entry Points") of the gracilis, adductor longus, adductor brevis, and adductor magnus muscle. Another study used bonylandmarks and two reference lines, longitudinal and horizontal, and described the superior-inferior and the mediolateral relationships between the NEPs of these four muscles (Crystal et al., 2005; Kwon et al., 2009). But the depth from skin surface of these NEPs and the NEPs of pectineus still remain unexplored. Viel et al. (2002) used both X-ray and electrical stimulator to guide the injection needle when introducing ethanol to the NEPs of obturator nerve. The procedure introduced multiple unnecessary needle punctures and high dose radiation to patients.

Based on our recently developed method of using spiral CT to localize the NEPs (Hu et al.; Yang et al., 2017a,b), in this study, through gross dissection, we used barium sulfate to label the NEPs (the points wherenerve branches enter muscle bellies) in thigh adductor muscles of adult cadavers, and identified the three-dimensional position of the NEPs by combining body surface bonylandmark measurements with spiral CT. This method may help therapists to target NEPs more quickly and precisely when using phenol or ethanol to block muscle spasticity.

\section{MATERIAL AND METHOD}

Specimens and ethics: This study was performed on the lower limbs of 20 formalin-fixed adult cadavers (12 men, 8 women) age 35-75 years at the time of death. No history of neuromuscular diseases and lower limb joint deformation were found. This experiment was approved by the ethics committee of our school.

Gross anatomy: Forty lower limbs of twenty adult cadavers were dissected in supine position. The skin and superficial fascia of the anterior thigh region were cut and reflected as one layer and the pectineus, adductor longus, and gracilis muscle were exposed. The NEP of pectineus muscle branch $(\mathrm{PMB})$ from the femoral nerve was revealed from lateral aspect. The NEPs of gracilis muscle branch (GMB), adductor longus muscle branch (ALMB), and adductor brevis muscle branch $(\mathrm{ABMB})$ were revealed by cutting the origin of adductor longus muscle at pubic bone and flipping the muscle distally. The NEP of the adductor magnus muscle branch (AMMB) was revealed by turning the adductor brevis superolaterally (Fig. 1). The number of neuromuscular branches, location of their muscle entry points, and the accompanying blood vessels were observed.

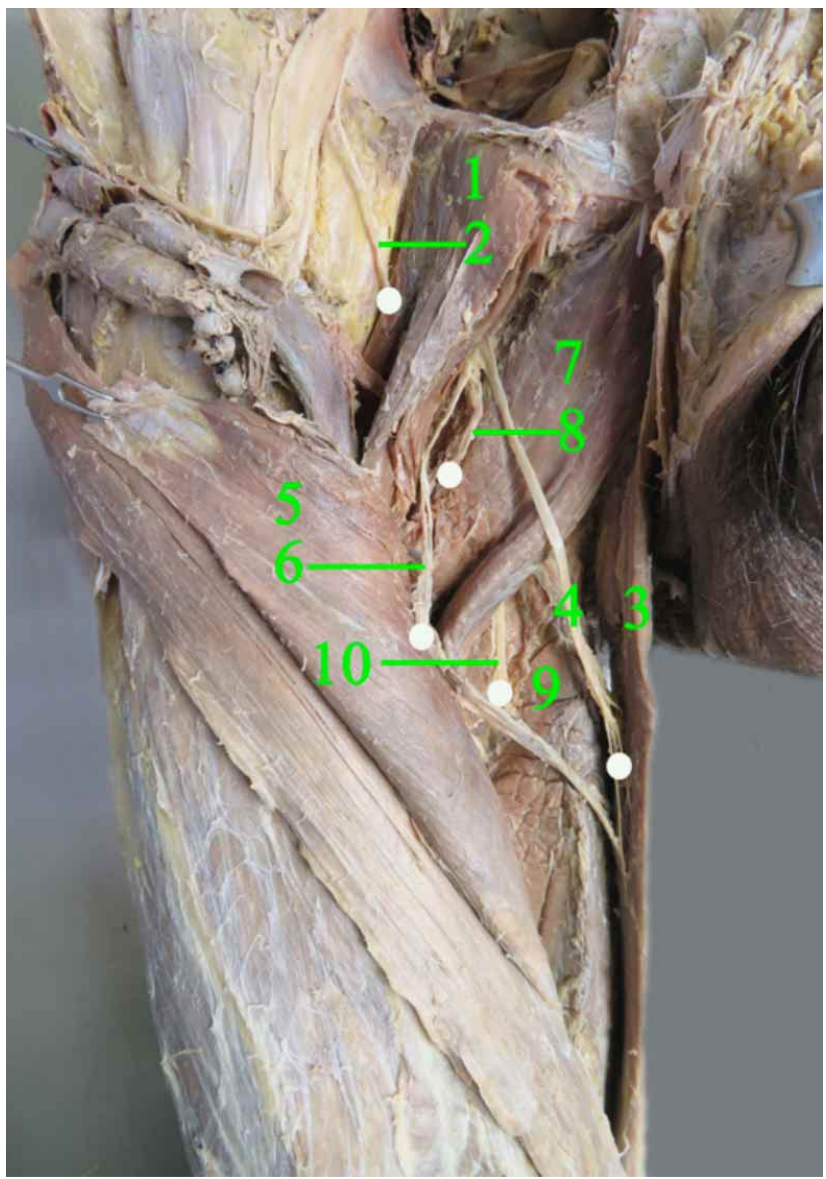

Fig. 1. Gross anatomy observation of the NEPs of thigh adductor muscles. $1=$ Pectineus muscle, $2=$ PMB belongs to femoral nerve, $3=$ Gracilis muscle, $4=\mathrm{GMB}, 5=$ Adductor longus muscle, $6=$ ALMB, $7=$ Adductor brevis muscle, $8=\mathrm{ABMB}, 9=$ Adductor magnus muscle, $10=\mathrm{AMMB}$. White dots indicate the NEPs of each nerve branch.

Reference line design: In order to describe the mediolateral and superioinferior relationship between NEPs and the bony landmarks, the greater trochanter of femur (A), lateral epicondyle of femur (B), and pubic tubercle (C) were chosen as bony landmarks for measurement. A curved line on skin surface joining the tip of greater trochanter of femur and the center of pubic tubercle was designated as horizontal reference line $(\mathrm{H})$. Another curved line joining the tip of great trochanter and the lateral epicondyle of femur was designated as longitudinal reference line (L) (Fig. 2A). 

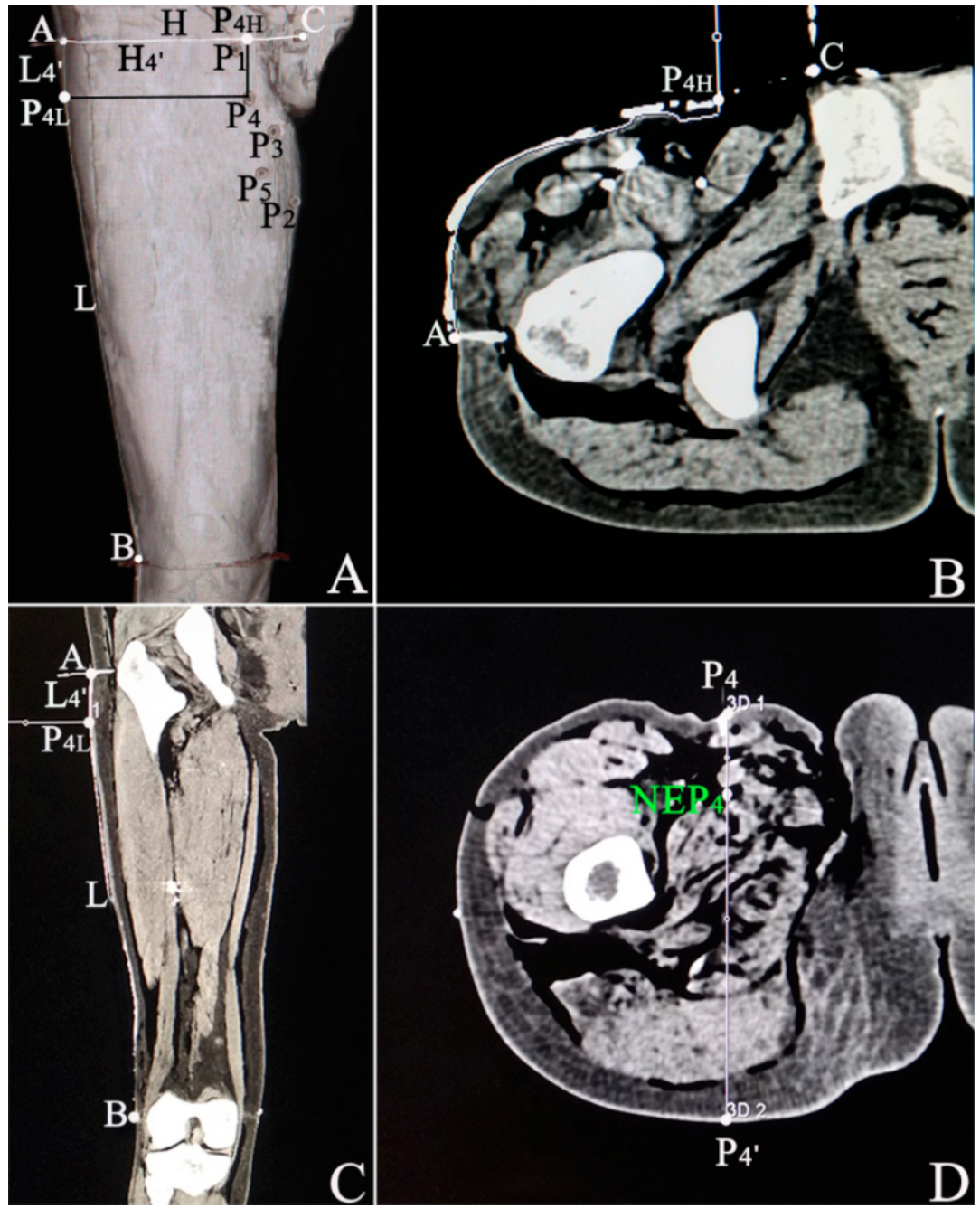

Fig. 2. Spiral CT images of the NEPs of the right thigh adductor muscles. Panel A: Three-dimensional reconstruction of spiral CT showed the position of NEPs on body surface as well as the reference lines. The body surface landmarks $\mathrm{A}=$ Greater trochanter of femur; $\mathrm{B}=$ lateral femoral epicondyle; $\mathrm{C}=$ pubic tubercle; $\mathrm{P} 1 \sim \mathrm{P} 5$ are the projection points of NEPs of pectineus, gracilis, adductor longus, adductor brevis and adductor magnus muscle, respectively. $\mathrm{AB}=$ longitudinal reference line $(\mathrm{L}), \mathrm{AC}=$ horizontal reference line $(\mathrm{H})$; A-P4L $=\mathrm{L} 4$ ', A-P4H $=\mathrm{H} 4$ ' (using adductor brevis muscle as an example). Panel B: A representative image of the length measurement of $\mathrm{H}$ and $\mathrm{H}$ ' lines on cross section (on adductor brevis muscle). Panel C: A representative image of the length measurement of $\mathrm{L}$ and $\mathrm{L}$ ' lines on coronal section (on adductor brevis muscle). Panel D: A representative image of NEP depth measurement (on adductor brevis muscle).

Localization of NEPs by spiral CT: The NEPs were labelled with barium sulfate combined with 801 glue (Wenzhou 801 Glue Co. Ltd., Wenzhou, China) and dried with a hair dryer, then the dissection was sutured at each layer to return to original anatomy. A needle was inserted on body surface at each bony landmark (A, B, and C) and barium sulfate-soaked silk thread were used to connect the needles. These silk threads were sutured to the skin surface and represent the $\mathrm{H}$ and L lines. Spiral CT (Siemens, Munich, Germany) scanning with 16-row was carried out $($ collimation $=64 \times 1$, slice thickness $=1 \mathrm{~mm}$, pitch $=1: 1$, current $=$ $120 \mathrm{kV}$ with automatic $\mathrm{mA}$ adjustment, thin layers with three-dimensional image reconstruction). The NEPs for each thigh adductor muscle was identified as the white spot that first-appeared on a cross section image when scanning from distal to proximal. At this section plane, a needle was inserted perpendicularly from medial thigh skin surface and aimed toward the identified NEP. The skin puncture point was then identified as the projection point (P point) for the identified NEP. The NEPs of pectineus, gracilis, adductor longus, adductor brevis and adductor magnus were labelled as NEP1, NEP2, NEP3, NEP4 and NEP5 respectively. The $P$ points of the relevant NEPs were labelled as P1, P2, P3, $\mathrm{P} 4$ and P5. The specimens were re-scanned again with $\mathrm{CT}$ for three-dimensional reconstruction. Acurved line measurement tool, Syngo System (Siemens Berlin, Germany), was used to measure the lengths of $\mathrm{H}$ line and $\mathrm{L}$ line on skin surface. When connecting $\mathrm{P}$ point perpendicularly to line $\mathrm{H}$, the intersecting point was designated as $\mathrm{PH}(\mathrm{P} 1 \mathrm{H}, \mathrm{P} 2 \mathrm{H}, \mathrm{P} 3 \mathrm{H}, \mathrm{P} 4 \mathrm{H}$ and $\mathrm{P} 5 \mathrm{H})$; the horizontal perpendicular line connecting $\mathrm{P}$ point to line $\mathrm{L}$ created an intersection point PL (P1L, P2L, P3L, P4L and P5L) (Fig. 2A-C). The distance from bony landmark $\mathrm{A}$ to $\mathrm{PH}$ was measured as $\mathrm{H}^{\prime}$ (H1', H2', H3', H4' and H5'). The distance from A to PL was identified as L' (L1', L2', L3', L4' and L5') (Fig. 2A-C). The position of NEPs on body surface was calculated by $\mathrm{H}^{\prime} / \mathrm{H} \times 100$ $\%$ and $\mathrm{L}^{\prime} / \mathrm{L} \times 100 \%$. When connecting P point to the related NEP on a cross section plane and extending the connecting line to the opposite side skin surface, an additional point, $\mathrm{P}^{\prime}$, was obtained on the opposite side skin surface and a line of PP' was defined. The depth of an NEP was identified on its $\mathrm{PP}^{\prime}$ line by calculating the value of $\mathrm{P}-\mathrm{NEP} / \mathrm{PP} \times 100$ $\%$ (Fig. 2D).

Statistical analysis. All measured data wasexpressed as percentages? $\pm \mathrm{S} ? \%$ in order to eliminate the variations of height and body weight between individuals. Data between left and right sides wascompared with paired t-test and $\mathrm{p}<$ 0.05 was adopted as statistical significance. 
CHEN, Y.; WANG, M.; ZHANG, X.; ZHANG, T. \& YANG, S. Localization of the nerve entry points of thigh adductor muscles by spiral computed tomography: A novel anatomical guide for chemical neurolysis in treating muscle spasticity. Int. J. Morphol., 36(3):871-876, 2018.

\section{RESULTS}

Gross anatomy observation: The trunk of the obturator nerve passes through the obturator externus muscle about $3 \mathrm{~cm}$ inferiolaterally to the pubic tubercle and divides into anterior and posterior branches, both of which travel superficial (anterior branch) and deep (posterior branch) to the adductor brevis muscle. The anterior branch sends more branches to gracilis, adductor longus and adductor brevis muscles, whereas the posterior branch goes to adductor magnus. Each muscular branch usually shows a single NEP. The gracilis branch reaches the muscle from deep surface atupper central region of muscle belly and divides into 2 4 sub-branches. The point where subbranches start to divide was designated as the NEP for this muscle. There are blood vessels at $1.5 \mathrm{~cm}$ below the NEP. The adductor longus branch travels inferiorly and enter the muscle in the upper region above the center of muscle belly with blood vessels accompanying at the NEP. The branch of adductor brevis enters the muscle in lateral region with vasculature accompanying under the NEP. Adductor magnus branch enters the muscle in the center region of the anterior surface and the NEP is accompanied by small vessels (Fig. 1). Ninety percent $(90 \%, 36 / 40)$ of the nerve branches of the pectineus comes from femoral nerve and reaches the middle-lateral region of the muscle deep to blood vessels, which are found $1 \mathrm{~cm}$ below the NEPs (Fig. 1). Ten percent $(10 \%, 4 / 40)$ pectineus samples are dually innervated by both femoral and obturator nerves. In this study, we focused on the NEPs from femoral nerve only.

Localization of NEPs with spiral CT: The NEPs as well as the reference lines labelled with barium sulfate were visualized as either white dots or lines under the three-dimensional reconstruction and the transverse section of spiral $\mathrm{CT}$. The P point, known as the projection point of a specific NEP on body surface, is the choice of puncture point for treatment injection. The length of $\mathrm{H}$ and $\mathrm{H}^{\prime}$ as well as $\mathrm{L}$ and L' on body surface can be measured with curve measurement tools. The length of P-NEP and PP' can be obtained on cross sections with a linear measurement tool. In this manuscript, we will use the NEP of adductor brevis muscle (NEP4) as a representative for analysis (Fig. 2A-D).

By analyzing all 40 lower limbs, we identified that the location of PH for the NEPs of PMB, GMB, ALMB, $\mathrm{ABMB}$ and $\mathrm{AMMB}$ were located at $76.41 \pm 0.71 \%$, $93.85 \pm 2.07 \%, 92.05 \pm 2.15 \%, 80.75 \pm 1.20 \%$ and $88.08 \pm 1.09$ $\%$ respectively on line $\mathrm{H}$ from the greater trochanter of femur. The PL were at $1.64 \pm 0.04 \%, 29.89 \pm 1.90 \%, 16.06 \pm 1.32 \%$, $11.66 \pm 0.11 \%$ and $22.94 \pm 0.90 \%$ respectively on line $\mathrm{L}$ from greater trochanter of femur. The depth of NEP from P points were at $17.52 \pm 0.52 \%, 38.38 \pm 2.75 \%, 20.88 \pm 0.79 \%$, $20.35 \pm 0.82 \%$ and $39.52 \pm 0.67 \%$ respectively on PP' from anterior skin surface (Table I). There were no statistical differences between left and right lower limbs ( $p>0.05)$.

Table I. The Location of PH and PL on Line H and Land the Depth of NEP on Line PP'.

\begin{tabular}{lccc}
\hline \multirow{2}{*}{ NEPs } & $\begin{array}{c}\text { Location of } \mathrm{P}_{\mathrm{H}} \text { o } \mathrm{H}(\%) \\
\mathrm{H}^{\prime} / \mathrm{H}(\%)\end{array}$ & $\begin{array}{c}\text { Location of } \mathrm{PL}_{\mathrm{L}} \text { on } \mathrm{L}(\%) \\
\mathrm{L} / \mathrm{L}(\%)\end{array}$ & $\begin{array}{c}\text { Depth of NEP }(\%) \\
\text { P-NEP/PP'(\%) }\end{array}$ \\
\hline PMB & $76.41 \pm 0.71$ & $1.64 \pm 0.04$ & $17.52 \pm 0.52$ \\
GMB & $93.85 \pm 2.07$ & $29.89 \pm 1.90$ & $38.38 \pm 2.75$ \\
ALMB & $92.05 \pm 2.15$ & $16.06 \pm 1.32$ & $20.88 \pm 0.79$ \\
ABMB & $80.75 \pm 1.20$ & $11.66 \pm 0.11$ & $20.35 \pm 0.82$ \\
AMMB & $88.08 \pm 1.09$ & $22.94 \pm 0.90$ & $39.52 \pm 0.67$ \\
\hline
\end{tabular}

\section{DISCUSSION}

The upper motor neuron dysfunction, such as in the cases of stroke, spinal cord injury, and multiple sclerosis, can usually cause the spasticity of thigh adductor muscles. The spasticity of these muscles can affect patients in perineal hygiene, siting, and standing with subsequently results in disruption of normal daily life (Kwon et al.). Thus, reducing the hyperactivity of thigh adductor muscles and increasing the range of activity of the hip joint are the key tasks to improve the life quality of these patients (Choi $e t$ al., 2011).
The chemical neurolysis, injecting phenol or ethanol to nerve branches at their entries to muscles, could induce the denaturalization of the proteins on endolemma and axons and help to decrease the activity of local nerve-muscle interaction, therefore preventing muscle contracture and improving the gait (Kocabas et al., 2010; Lee et al., 2011; Karri et al., 2017). This therapy is beneficial to patients by reducing muscle hyperactivity, increasing hip joint moving range, and improving perineal hygiene (Ghai et al., 2012; Yalcin et al., 2014; Chang, 2017). Although X-ray imaging, 
electrical stimulator, ultrasound, and other equipment are used in this procedure (Akkaya et al., 2010; Yoshida et al.; Matsumoto et al., 2018), the clinical effect of this therapy is limited by the inaccuracy in finding the precise location of the blocking target. Therefore, obtaining accurate anatomical information about NEP locations becomes necessary.

Blocking large nerve trunks is relatively easy to do but it causes unrelated areas' paresthesia and involves nonspastic muscles. The NEPs are located closer to motor endplate and blocking them requires shorter axonal regenerative time. Thus, blocking the NEPs has a lot more advantages over blocking the large nerve trunk (Yang et al., 2017a,b). The anatomical analysis of NEPs (some authors named them "Motor Points") in thigh adductor muscles has been reported before. Crystal et al. chose the line joining the synchondroses pubis and the medial femoral condyle as the reference line on body surface, and then measured the position of the motor points of gracilis, adductor longus, adductor brevis and adductor magnus muscle on the reference line. But this study did not consider the mediolateral relationship between NEP and the bony landmarks (Crystal et al.). Kwon et al. designated the connecting line between pubic tubercle and medial femoral epicondyle as the longitudinal reference line, the connecting line from pubic tubercle to greater trochanter of femur as the horizontal reference line. However, although the superior-inferior and mediolateral positioning of the NEPs of the above-mentioned muscles were described, the measurement of NEP depth and the analysis of pectineus have not been studied (Kwon et al.). In addition, these studiesdid not match the exact projection of the NEPs on body surface because they were done by measuring the linear distance from NEPs to bony landmarks on dissected specimens. Our study analyzed the NEPs by spiral CT with the three-dimensional reconstruction and projected the NEPs onto body surface. The position of NEPs were measured by curve measurement tool close to skin, which help to measure the puncture depth precisely. From our results, the NEPs of gracilis, adductor longus, adductor brevis and adductor magnus muscle showed different body surface puncturing positions comparing with the abovementioned studies. This difference may due to the different of bony landmarks selection and a novel localizing method by spiral CT. In our study, we selected the connecting line from greater trochanter of femur to lateral femoral epicondyle as the longitudinal reference line rather than the connecting line between pubic tubercle and medial femoral epicondyle. This selection is based on skin transition between the pubic tubercle and the root of the thigh. Measuring the distance between pubic tubercle and the medial epicondyle of the femur may produce inaccuracy due to the characteristics of this area.
Based on the results of this study, we suggest that during the practice of chemical neurolysis treatment to thigh adductor muscles spasticity, one could measure on body surface the length between greater trochanter of femur and pubic tubercle ( $\mathrm{H}$ line), and the length from greater trochanter of femur to lateral epicondyle of femur (L line). Then, draw vertical lines off the $\mathrm{H}$ line at $76.41 \pm 0.71 \%, 93.85 \pm 2.07 \%$, $92.05 \pm 2.15 \%, 80.75 \pm 1.20 \%$ and $88.08 \pm 1.09 \%$ length of the line, draw horizontal lines off the $\mathrm{L}$ line at $1.64 \pm 0.04 \%$, $29.89 \pm 1.90 \%, 16.06 \pm 1.32 \%, 11.66 \pm 0.11 \%$ and $22.94 \pm 0.90$ $\%$ length of $\mathrm{L}$ line. The intersection points between the vertical and horizontal lines are the puncture points of various NEPs. The depth of NEPs is measured on PP' line with a pelvimeter or vernier caliper on the cross-sectional plane. The depth of each NEP should be 17.52 $\pm 0.52 \%, 38.38 \pm 2.75 \%$, $20.88 \pm 0.79 \%, 20.35 \pm 0.82 \%$ and $39.52 \pm 0.67 \%$ respectively on PP' line. It is noteworthy that all above-mentioned 5 NEPs are all accompanied with blood vessels. Therefore, pulling back the plunger is needed before injecting the medication.

Taken together, we established the geometric relationship between NEPs and bony landmarks through spiral CT scanning and three-dimensional image reconstruction. This method provides relatively more precise location of the NEPs on the body surface of the thigh adductor muscles (including pectineus). In addition, this study provided data for puncture depth. We hope that our method can help to increase the therapeutic effects and improve the efficiency of chemical neurolysis in treating spasticity. However, we still suggest combine our method with the usage of ultrasound and electrical stimulator for localizing the NEPs more accurately during the clinical practice.

\section{CONCLUSIONS}

These results help to carry out more precise localization of the NEPs. It should provide a novel anatomical guide for improving the efficacy and efficiency of chemical neurolysis in treating thigh adductor muscle spasticity.

ACKNOWLEDGMENTS. The authors would like to acknowledge Shuangjiang $\mathrm{Hu}$ and Xufeng Tian for their excellent technical assistance and use of their spiral CT laboratory. We also would like to express our sincere gratitude to the 20 body donors who were anonymous teachers helped us to complete the project. This work was supported by the National Natural Science Foundation of China (31540031, 31660294) and the Provincial Natural Science Joint Foundation of Guizhou (LH-2015-7528). 
CHEN, Y.; WANG, M.; ZHANG, X.; ZHANG, T. \& YANG, S. Localización de los puntos de entrada del nervio de los músculos aductores del muslo mediante tomografía computarizada en espiral: Una nueva guía anatómica para la neurólisis química en el tratamiento de la espasticidad muscular. Int. J. Morphol., 36(3):871-876, 2018.

RESUMEN: Aún no se pueden localizar con precisión los puntos de entrada del nervio (PEN) para el tratamiento de la espasticidad de los músculos aductores del muslo a través de la neurólisis química. El objetivo de este estudio fue identificar la ubicación y la profundidad de los PEN de los músculos aductores del muslo mediante tomografía computarizada espiral (TC) y puntos de referencia óseos. Se disecaron loa miembros inferiores de 20 cadáveres adultos en posición supina. Se trazó una línea curva en la superficie de la piel desdeel ápice del trocánter mayor del fémur hasta el centro del tubérculo púbico y se designó como línea de referencia horizontal (H). Otra línea curva desde el ápice del trocánter mayor hasta el epicóndilo lateral del fémur se designó como línea de referencia longitudinal (L). Después de la disección, los PEN se marcaron con sulfato de bario y sus puntos de proyección de la superficie del cuerpo $(\mathrm{P})$ se determinaron mediante TC helicoidal. La proyección de PEN en la dirección opuesta se designó como $\mathrm{P}$ '. El porcentaje de ubicación de las intersecciones (PH y PL) de $\mathrm{P}$ con $\mathrm{H}$ y L y la profundidad porcentual de los PEN se determinaron con el sistema Syngo. Los PH para los PEN de los músculos pectineus, gracilis, adductor longus, aductor brevis y rama aductora del músculo aductor magnus se localizaron en 76,41 $\pm 0,71 \%, 93,85 \pm 2,07 \%$, $92,05 \pm 2,15 \%, 80,75 \pm 1,20 \%$ y $88,08 \pm 1,09 \%$ de $\mathrm{H}$, respectivamente. Los PL estuvieron en $1,64 \pm 0,04 \%, 29,89 \pm 1,90 \%, 16,06 \pm 1,32 \%$, $11,66 \pm 0,11 \%$ y $22,94 \pm 0,90 \%$ de la $\mathrm{L}$, respectivamente. La profundidad de PEN de P puntos fue de 17,52 $\pm 0,52 \%, 38,38 \pm 2,75 \%, 20,88 \pm 0,79$ $\%, 20,35 \pm 0,82 \%$ y $39,52 \pm 0,67 \%$ de PP ', respectivamente. Estos resultados ayudan a realizar una localización más precisa de los PEN. Se debe proponer una nueva guía anatómica para mejorar la eficacia y la eficiencia de la neurólisis química en el tratamiento de la espasticidad del músculo aductor del muslo.

PALABRAS CLAVE: Puntos de entrada del nervio; Localización; Músculos aductores del muslo; Espasticidad; Tomografía computarizada espiral.

\section{REFERENCES}

Akkaya, T.; Unlu, E.; Alptekin, A.; Gumus, H. I.; Umay, E. \& Cakci, A. Neurolytic phenol blockade of the obturator nerve for severe adductor spasticity. Acta. Anaesthesiol. Scand., 54(1):79-85, 2010.

Alabdulwahab, S. S. \& Al-Gabbani, M. Transcutaneous electrical nerve stimulation of hip adductors improves gait parameters of children with spastic diplegic cerebral palsy. NeuroRehabilitation, 26(2):115-22, 2010.

Chang, M. C. Reduced foot pain after spasticity control with alcohol block in a patient with chronic hemiparetic stroke: a case report. J. Phys. Ther. Sci., 29(4):767-70, 2017.

Choi, E. J.; Byun, J. M.; Nahm, F. S. \& Lee, P. B. Obturator nerve block with botulinum toxin type B for patient with adductor thigh muscle spasm -a case report-. Korean J. Pain, 24(3):164-8, 2011.

Cioncoloni, D.; Taddei, S.; Bielli, S.; Annunziata, P. \& Mazzocchio, R. Meaningful improvement in walking performance after Botulinum neurotoxin A (BoNT-A) in chronic spastic patients. NeuroRehabilitation, 34(1):185-92, 2014.

Crystal, R.; Malone, A. A. \& Eastwood, D. M. Motor points for neuromuscular blockade of the adductor muscle group. Clin. Orthop. Relat. Res., (437):196200, 2005 .
Ghai, A.; Sangwan, S. S.; Hooda, S.; Kiran, S. \& Garg, N. Obturator neurolysis using $65 \%$ alcohol for adductor muscle spasticity. Saudi. J. Anaesth., 6(3):282-4, 2012

Hu, S.; Zhuo, L.; Zhang, X. \& Yang, S. Localization of nerve entry points as targets to block spasticity of the deep posterior compartment muscles of the leg. Clin. Anat., 30(7):855-60, 2017.

Karri, J.; Mas, M. F.; Francisco, G. E. \& Li, S. Practice patterns for spasticity management with phenol neurolysis. J. Rehabil. Med., 49(6):482-8, 2017.

Khot, A.; Sloan, S.; Desai, S.; Harvey, A.; Wolfe, R. \& Graham, H. K. Adductor release and chemodenervation in children with cerebral palsy: a pilot study in 16 children. J. Child. Orthop., 2(4):293-9, 2008.

Kocabas, H.; Salli, A.; Demir, A. H. \& Ozerbil, O. M. Comparison of phenol and alcohol neurolysis of tibial nerve motor branches to the gastrocnemius muscle for treatment of spastic foot after stroke: a randomized controlled pilot study. Eur. J. Phys. Rehabil. Med., 46(1):5-10, 2010.

Kwon, J. Y.; Kim, J. S. \& Lee, W. I. Anatomic localization of motor points of hip adductors. Am. J. Phys. Med. Rehabil., 88(4):336-41, 2009.

Lam, K.; Wong, D.; Tam, C. K.; Wah, S. H.; Myint, M. W.; Yu, T. K.; So, K. K.; Cheung, G.; Au, K. M.; Fu, M. H.; Wu, Y. M. \& Kng, C. P. Ultrasound and electrical stimulator-guided obturator nerve block with phenol in the treatment of hip adductor spasticity in long-term care patients: a randomized, triple blind, placebo controlled study. J. Am. Med. Dir. Assoc., 16(3):23846, 2015.

Lee, J. H.; Lee, B. N.; An, X.; Chung, R. H.; Kwon, S. O. \& Han, S. H. Anatomic localization of motor entry point of superficial peroneal nerve to peroneus longus and brevis muscles. Clin. Anat., 24(2):232-6, 2011.

Matsumoto, M. E.; Berry, J.; Yung, H.; Matsumoto, M. \& Munin, M. C. Comparing electrical stimulation with and without ultrasound guidance for phenol neurolysis to the musculocutaneous nerve. PM. R. 10(4):357-64, 2018.

Murphy, A. M.; Milo-Manson, G.; Best, A.; Campbell, K. A. \& Fehlings, D. Impact of modafinil on spasticity reduction and quality of life in children with CP. Dev. Med. Child. Neurol., 50(7):510-4, 2008.

Qureshi, A. Z. \& Adiga, S. Adductor tenotomy and selective obturator neurectomy for the treatment of spasticity in a man with paraplegia. J. Spinal Cord. Med., 36(1):36-9, 2013

Viel, E. J.; Perennou, D.; Ripart, J.; Pélissier, J. \& Eledjam, J. J. Neurolytic blockade of the obturator nerve for intractable spasticity of adductor thigh muscles. Eur. J. Pain., 6(2):97-104, 2002.

Ward, A. B. Spasticity treatment with botulinum toxins. J. Neural Transm. (Vienna), 115(4):607-16, 2008.

Woodburne, R. T. The accessory obturator nerve and the innervation of the pectineus muscle. Anat. Rec., 136:367-9, 1960.

Yalcin, E.; Akyuz, M.; Ilgu, O. \& Ozer, N. B. Ultrasonographically guided obturator nerve block for bilateral adductor spasticity in a paraplegic patient. Spinal Cord, 52 Suppl. 2:S24-6, 2014.

Yang, S.; Hu, S.; Li, B. \& Li, X. Localization of nerve entry point and intramuscular nerve-dense regions as targets to block brachioradialis muscle spasticity. Int. J. Clin. Exp. Med., 10(8):11912-20, 2017a.

Yang, S.; Hu, S.; Tian, X. \& Hu, S. A novel method for localizing nerve entry points during spasticity treatment. Int. J. Morphol., 35(3):799-803, $2017 \mathrm{~b}$.

Yoshida, T.; Nakamoto, T. \& Kamibayashi, T. Ultrasound-guided obturator nerve block: A focused review on anatomy and updated techniques. BioMed Res. Int., 2017:7023750, 2017.

\section{Corresponding author:}

Prof. Shengbo Yang

Department of Anatomy

Zunyi Medical College 6 UniversityWest Road

Xinpu New Developing Areas

Zunyi City, 563000, Guizhou Province People's

REPUBLIC OF CHINA

E-mail: yangshengbo8205486@163.com

Recibido : 28-01-2018

Aceptado: 23-04-2018 